\title{
SUR LES CONIQUES DÉTERMINÉES PAR CINQ CONDITIONS DE CONTACT AVEC UNE COURBE DONNÉE.
}

[From the Comptes Rendus de l'Académie des Sciences à Paris, tom. LXIII. (JuilletDécembre, 1866), pp. 9-12.]

This paper (dated Cambridge, 26 June 1866), contains the expressions for the numbers $(5),(4,1),(3,2)$ $(3,1,1),(2,2,1),(2,1,1,1)$ and $(1,1,1,1,1)$, of the conics which satisfy five conditions of contact with a given curve, as obtained in the paper 406 "On the Curves which satisfy given conditions," see p. 214, and which expressions were found by the same process, viz. by consideration of functional equations obtained by supposing the given curve to break up into two curves of the orders $m$ and $m^{\prime}$ respectively; there was in the expression for $(1,1,1,1,1)$ a numerical error as mentioned in the footnote of the same page. The paper contains also the formula $\mu^{\prime \prime}-\frac{3}{2} \nu^{\prime \prime}+\frac{3}{2} \rho^{\prime \prime}-\sigma^{\prime \prime}=0$, and the expression for $(2 X, 3 Z)$ given, pp. 203,204 . 